This tension upon the capsule causes it, when its strength is sufficient, to flatten the surfaces of the lens."

Now, according to Fig. 9, its strength is greater in the periphery than at the centre, and, therefore, on the author's explanation we should expect to find a more curved centre but a flatter periphery. But Fig. 8 appears to show the converse. It should be pointed out that on page 25 , line 15 , the author says : "the resultant surface would show a greater curvature in the centre than towards the periphery. Such a form was found to exist in the anterior surface of the lens in Case M. in the unaccommodated state." This statement agrees exactly with the author's conclusion. It would seem clear from this that a slip has occurred in the drawing of Fig. 8. If this is the case Fincham's results are in unequivocal agreement with Helmholtz's theory, and with those obtained by Yamada and myself (Brit. Jl. of Ophthal., Vol VI, p. 481, 1922): We found that if the crystalline lenses were removed from the cat's eyes they were in the fully accommodated state, and we concluded also that the peripheral parts of the anterior lens surface suffer a relative but not an actual flattening on accommodation. Both these conclusions are antagonistic to Tscherning's views.

I should like to complete this brief survey by expressing, firstly, my admiration for Fincham's researches, and, secondly, my hope that he will extend his researches to many more cases, not youths alone but also middle-aged. For the precise nature of the lens changes in presbyopia is practically unknown. It seems to me that the time has come to regard presbyopia as a disease and not as a normal physiological process.

\title{
ANNOTATION
}

\section{Lacrymal Obstruction}

Thirty years or so ago it was customary to treat our lacrymal cases in general by the old-fashioned method of probing and lavage. It is true that we gave our patients rather a bad time, but cocain was a great help as the following story shows. The writer had been in the habit of regularly passing probes on a working-class woman who habitually said nothing during the process. On only one occasion did she speak, and to the point. What she said was "Ach doctor! you're awfu' coorse the day." The cocain had been omitted. Hinc illae lacrimae. To continue, we were not satisfied with probing and there came a time when it was almost 
malpraxis to slit the canaliculus or to pass a probe. So we excised the sac, an operation which was often extremely satisfactory not only as regards the removal of a septic focus but also in that lacrymation afterwards was not so troublesome as might be expected. But still we-speaking purely in an impersonal sense -were not satisfied so went a step further and developed various operative procedures to obtain free drainage into the nose. What is the result? At a recent meeting of the Section of Ophthalmology of the Royal Society of Medicine a paper was read by a wellknown ophthalmic surgeon on methods of operating in cases of suppurative dacryocystitis. These methods involved the making of an opening through the sac into the middle meatus of the nose. To judge from the report of the proceedings in our contemporary the Lancet (June 2\%, 1925) the proposals were received with what one might almost call a chorus of disapproval.

In order to avoid personalities for the present, we may put it that the voices in the chorus expressed the following opinions: That epiphora must still exist after the operation; that there was danger of a fistula from the nose to the face after the operation: that after West's operation the opening tended to close up and the patient was no better than before; that there was liability to general infection of the ethmoid cells. Have we, as usual, gone too far and must we retrace our steps? The answer is difficult.

\section{ABSTRACTS}

\section{I.-ACCOMMODATION}

(I) Fincham, E. F.- The changes in the form of the crystalline lens in accommodation. Trans. Optical Soc., Vol. XXVI, No. 5, 1924-1925.

(1) The original object of the investigation, so Fincham tells us, was to determine the form of the lens in various states of accommodation. It was hoped that from measurements of a number of eyes a set of curves could be plotted which would show the thickness of the lens and the radii of its surfaces for every state of accommodation in the average eye.

A number of preliminary measurements were made upon the radius of the anterior surface of the lens in different eyes, but it was found that this value varied over a wide range for the same condition of accommodation. Two cases were found, both males of the same age and having an equal error of refraction; the 